\title{
A Comparison of Emergence Characteristics with the use of Isoflurane, Sevoflurane and Desflurane in Patients Undergoing Spinal Surgeries under General Anaesthesia
}

\author{
Priyamvada Gupta ${ }^{1}$, Pooja Mongia ${ }^{2}$, Durga Jethava ${ }^{3}$, Sudhir Sachdev ${ }^{4}$ \\ ${ }^{1}$ Professor (Dept.Of Anaesthesiology, ${ }^{2}$ Postgraduate Student (Dept.Of Anaesthesiology, \\ ${ }^{3}$ Phod(Dept.Of Anaesthesiology, ${ }^{4}$ Professor(Dept.Of Anaesthesiology, \\ Mahatma Gandhi Medical College/ Mahatma Gandhi University Of Medical Science And \\ Technology,Jaipur,Rajasthan, India)
}

\begin{abstract}
Isoflurane is commonly used agent in neuro anaesthesia. But desflurane has lowest blood gas partition co efficient and has rapid recovery profile. Hence it may have useful role in spine surgeries. There is paucity of data regarding comparison of desflurane, sevoflurane and isoflurane in neuroanaesthesia in adult patients in a single study. Hence the need of present study. Ninety ASA I/II patients aged 20-60 yrs were randomly allocated into three groups of thirty each. Group D, Group S, group I received desflurane, sevoflurane and isoflurane respectively. The primary outcome studied was time to emergence: the time from discontinuation of anaesthetic agents to open eyes either spontaneously or in response to verbal commands. The secondary outcomes studied were time to extubation, time to recovery, haemodyanamic variations and complications if any. Data were analyzed using chi square, student $t$ and ANOVA tests as applicable. $p$ value $<0.05$ was considered statistically significant.The mean emergence time was shorter in desflurane group $(3.32 \pm 2.28 \mathrm{~min})$ as compared sevoflurane $(6.13 \pm 2.56 \mathrm{~min})$ and isoflurane $(7.93 \pm 2.02 \mathrm{~min})$ groups $(p<0.001)$ .Similar statistical difference was achieved in extubation and recovery times. Hence desflurane is better suited volatile halogenated agent for adult patients undergoing spine surgeries performed under general anaesthesia. Keywords : desflurane, extubation, isoflurane, sevoflurane, spinal surgery
\end{abstract}

\section{Introduction}

Anaesthesia for spinal surgeries is challenging in many ways namely wide fluctuations in blood pressure due to the prone position, blood loss and resulting organ damage. [1] Moreover the patient should have adequate peri operative analgesia and rapid recovery so as to enable the neurological assessment at the earliest. This plays a critical role in timely detecting the development of any new neurological deficit.

Isoflurane is most widely used inhalational agent in neuro anaesthesia since it causes minimal alteration in cerebral blood flow (CBF) and intracranial pressures (ICP) in hypocapnic patients. Sevoflurane has low blood: gas partition coefficient thus favouring rapid emergence. Desflurane in addition favours further rapid recovery due to low tissue blood partition coefficient[2]. They provide adequate haemodynamic stability during balanced anaesthesia in neurosurgical patients. The use of desflurane in neuro anaesthesia is controversial as it produces cerebral vasodilation. However some studies confirm that the effects of desflurane on ICP and CBF are similar to isoflurane[3].

There are few studies comparing the effects of isoflurane with sevoflurane and sevoflurane with desflurane in neurosurgical patients[5]. However there is paucity of data available comparing all the three volatile agents in spine surgeries in adult population in a single study. Hence this prospective randomized comparative study was carried out to compare the effects of isoflurane, sevoflurane and desflurane on emergence in adult patients undergoing spine surgeries under general anaesthesia.

\section{Materials \& Methods}

With the approval of the institutional ethical committee and informed written consent of patients, ninety patients scheduled for spine surgery were enrolled in this prospective randomized comparative study. Inclusion criteria: American Society of Anaesthesiologists(ASA) grade I/ II, age 20-60 years, either gender, preoperative Glasgow Coma Scale of fifteen. Exclusion criteria: hypertension, ischaemic or congestive heart disease, hepatic or renal dysfunction, chronic obstructive lung disease, diabetes mellitus, pregnancy, morbid obesity, anaemia, drug allergy, history of alcohol/drug abuse or psychiatric disorder. Patients who were electively planned for post-operative mechanical ventilation were also excluded. There was no drop out in any of the study groups.

Prior to induction of anaesthesia the patients were randomized into three equal groups ( $\mathrm{n}=30)$ : group I (isoflurane), group S (sevoflurane), Group D (desflurane) respectively. Randomization was done by computer 
generated random numbers. On the day of surgery on arrival in the operation room, monitoring was set upincluding electrocardiogram( $\mathrm{ECG})$, invasive blood pressure, end tidal carbon dioxide measurement $\left(\mathrm{EtCO}_{2}\right)$, pulse oximetry $\left(\mathrm{SpO}_{2}\right)$, central venous pressure(CVP), nasopharyngeal temperature and urine output charting.

The patients were premedicated with glycopyrrolate $0.2 \mathrm{mg}$ and fentanyl $2 \mu \mathrm{g} / \mathrm{kg}$ administered intravenously. Induction was achieved with preservative free xylocaine $2 \%$ in the dose of $2 \mathrm{mg} / \mathrm{kg}$ followed by propofol $2-2.5 \mathrm{mg} / \mathrm{kg}$ intravenously sufficient to abolish eye lash reflex. Endo tracheal intubation was aided by vecuronium $0.1 \mathrm{mg} / \mathrm{kg}$ intravenously administered 2 minutes prior to propofol. As per the group the inhalational agent was started soon after induction and maintained at minimum alveolar concentration (MAC) of 0.8 - 1.2 $\%$ with nitrous oxide and oxygen. The mechanical ventilation was adjusted to achieve the end tidal concentration of 32-35 mmHg. Muscle relaxation was maintained with intermittent bolus doses of vecuronium. The patients were turned to prone position once induction was complete.

Heart rate (HR), mean arterial pressure (MAP), $\mathrm{EtCO}_{2}$ and $\mathrm{SpO}_{2}$ were recorded just before induction, immediately after intubation, at the point of skin incision, at the time of laminectomy, every 15 minutes until the point of skin closure, just before extubation, just after extubation, after 5 minutes, 10 minutes, 15 minutes and thereafter at an interval of 15 minutes till 2 hours. Increase in HR and MAP more than $20 \%$ of the baseline was considered abnormal and managed by increasing the concentration of inhalational agent and propofol bolus dose of $30 \mathrm{mg}$ and/or fentanyl $50 \mu \mathrm{g}$ intravenously. If the $\mathrm{HR}$ value $<50 /$ minute for over $1 \mathrm{~min}$ atropine was administered $0.6 \mathrm{mg}$ intravenously; if MAP $<60 \mathrm{~mm} \mathrm{Hg}$ for over1 minute, the concentration of inhalational drug was reduced to $0.8 \%$ and bolus of intravenous fluid (ringer acetate) was administered. Total dose of fentanyl and vecuronium were recorded.

Ondansetron 4mg and paracetamol $1 \mathrm{gm}$ were given intravenously at the time of start of closure. On completion of surgery and return to supine position the anaesthetic agents were discontinued, stop clock on the monitor was started and time to emergence, time to extubation, time to recovery were noted. Neostigmine $0.05 \mathrm{mg} / \mathrm{kg}$ and glycopyrrolate $0.008 \mathrm{mg} / \mathrm{kg}$ were administered intravenously to reverse the neuromuscular blockade. Endotracheal extubation was done on return of adequate rate $\&$ depth of respiration and airway reflexes. After extubation patients were categorised as agitated, calm or sedated according to the Richmond's Agitation Sedation Scale. [5] Scores $\geq+1$ were considered to be agitated and required constraint. Patients were also categorised on the basis of cough (mild /moderate/severe) following extubation.

The primary outcome studied was time to emergence: the time from discontinuation of anaesthetic agents to eye opening either spontaneously or in response to verbal commands. [6] The secondary outcomes studied were time to extubation, time to recovery, haemodyanamic variations and complications if any. Time to extubation was the time between discontinuation of anaesthetic agent and extubation [6].The time between anaesthetic discontinuation and ability to recall name and date of birth was considered as time to recovery ${ }^{6}$.

In the post anaesthesia care unit, time to reach Modified Aldrete Score(MAS) $\geq 9$ was recorded Patients were also monitored for any postoperative complications like nausea and vomiting[7], respiratory depression $\left(\mathrm{SpO}_{2} \leq 95 \%\right)$, convulsions and pain during the first post-operative hour by the recovery room nurse. Pain was analysed on the basis of 10 point Visual Analogue Scale $(0=$ no pain, 1-3= mild pain, $4-6=$ moderate pain and 7-10 = severe pain) [8]. Score $>5$ was followed by diclofenac $75 \mathrm{mg}$ intravenously. Time to first dose of rescue analgesia was also recorded.

There did not occur any conflicts of interest. Few limitations were present in our study: blinding could not be done since the vaporisers are colour coded hence there remained the possibility of bias, we did not use neurological monitoring like bi spectral index (BIS) or entropy. Use of such monitoring would have reduced the doses and could have given precise results of emergence characteristics. Moreover we could have also studied evoked potentials. Since emergency and trauma surgery is increasing day by day, in future more studies can be done regarding use of desflurane in patients with trauma and co morbid illnesses like renal/hepatic/pulmonary/heart diseases as regards to rapid emergence and haemodynamic stability.

Statistical analysis was performed with the SPSS(Statistical Package for Social Sciences), trial version 20 for Windows statistical software package (SPSS inc., Chicago, Illinois, USA). The qualitative data were represented as numbers (percent) and the inter-group data comparison was done using chi square test. Demographic data were presented as mean \pm standard deviation and were compared using by students t-test and ANOVA(Analysis Of Variants) test as applicable, $\mathrm{p}$ value $<0.05$ was considered statistically significant.

Sample size calculation for this study was based on time of emergence (minutes). A clinically relevant difference between the treatment groups was defined as 5.5minutes. With an assumed standard deviation of 2 minutes and $\alpha$ level of 0.05 minutes, four patients in each group were required to obtain a power of $80 \%$. So for the study purpose we finally included thirty cases in each group.

\section{Results}

The demographic data was comparable among the study groups (TABLE 1). Total doses of fentanyl \& vecuronium, total intravenous fluids used, total urine output, total blood loss were all comparable among the 
study groups (table 1). The mean emergence time was longer in shorter in isoflurane $(7.93 \pm 2.02$ minutes) and sevoflurane $(6.13 \pm 2.56$ minutes $)$ groups as compared to desflurane group $(3.32 \pm 2.28$ minutes $)$. This was statistically significant $(\mathrm{p}<0.001)$. Extubation and recovery times (TABLE 2$)$ also depicted similar trends. The post operative pain score and time to first dose of rescue analgesia were also comparable (TABLE 3).Haemodynamic parameters were comparable at most points of time except that heart rate during and after emergence were significantly higher in isoflurane and sevoflurane groups as compared to the desflurane group (GRAPH 1,2).

\section{Figures And Tables}

Table 1: Demographics and intra operative data.

\begin{tabular}{|l|l|l|l|l|}
\hline Variable & Group I $(\mathrm{n}=30)$ & Group S(n=30) & Group D(n=30) & P value \\
\hline Age(yrs) & $45.8 \pm 14.01$ & $42.43 \pm 13.37$ & $44.53 \pm 12.39$ & 0.613 \\
\hline Weight(kg) & $71.23 \pm 7.568$ & $69.86 \pm 8.23$ & $68.96 \pm 8.15$ & 0.54 \\
\hline Female:Male & $10: 20$ & $8: 22$ & $7: 23$ & - \\
\hline Total dose of fentanyl (mcg) & $142.13 \pm 14.374$ & $140.07 \pm 15.892$ & $137.93 \pm 16.311$ & 0.58 \\
\hline $\begin{array}{l}\text { Total dose of vecuronium } \\
(\mathrm{mg})\end{array}$ & $7.53 \pm 1.04$ & $9.63 \pm 2.20$ & $7.3 \pm 1.9$ & 0.378 \\
\hline Urine output(ml) & $314.97 \pm 152$. & $390.33 \pm 186.28$ & $403.33 \pm 211.7$ & 0.143 \\
\hline Intravenous fluids(1) & $2.58 \pm 0.66$ & $2.7 \pm 0.59$ & $2.63 \pm 0.7$ & 0.745 \\
\hline Blood loss (ml) & $116.5 \pm 68.7$ & $164 \pm 127.59$ & $196 \pm 154.69$ & 0.045 \\
\hline $\begin{array}{l}\text { Total duration of anesthesia } \\
\text { (min) }\end{array}$ & $136.50 \pm 30.602$ & $132.00 \pm 31.856$ & $128.93 \pm 31.133$ & 0.64 \\
\hline $\begin{array}{l}\text { Type of surgery } \\
\text { Spinal tumours }\end{array}$ & $2(6.67 \%)$ & $6(20 \%)$ & & 0.433 \\
\cline { 1 - 2 } $\begin{array}{l}\text { Cervical laminectomies } \\
\text { Lumbar laminectomies }\end{array}$ & $6(20 \%)$ & $4(13.33 \%)$ & $3(10 \%)$ & \\
\cline { 1 - 2 } & $22(73.33 \%)$ & $20(66.67 \%)$ & $24(80 \%)$ & \\
\hline
\end{tabular}

$\mathrm{n}=$ number of patients

Table 2: Emergence characteristics:

\begin{tabular}{|l|l|l|l|l|}
\hline Variable & Group I $(\mathrm{n}=30)$ & Group S(n=30) & Group D(n=30) & P value \\
\hline Time to emergence $(\min )$ & $7.93 \pm 2.02$ & $6.13 \pm 2.56$ & $3.32 \pm 2.28$ & $<0.001$ \\
\hline Time to extubation(min) & $9.97 \pm 1.97$ & $8.40 \pm 2.59$ & $4.88 \pm 2.27$ & $<0.001$ \\
\hline Time to recovery $(\min )$ & $12.9 \pm 2.35$ & $9.8 \pm 2.66$ & $5.65 \pm 2.8$ & $<0.001$ \\
\hline
\end{tabular}

$\mathrm{n}=$ number of patients

Table 3: Post-operative data.

\begin{tabular}{|l|l|l|l|c|}
\hline Variable & Group I(N=30) & Group S(N=30) & Group D(N=30) & P value \\
\hline $\begin{array}{l}\text { Time to achieve Modified } \\
\text { Aldrete Score } 9(\mathrm{~min})\end{array}$ & $15.10 \pm 2.398$ & $12.00 \pm 2.691$ & $7.70 \pm 2.680$ & $<0.001$ \\
\hline Visual Analogue Score & $3.6 \pm 0.77$ & $4.2 \pm 1.54$ & $3.5 \pm 1.28$ & 0.060 \\
\hline $\begin{array}{l}\text { Time of first dose of } \\
\text { analgesia(min) }\end{array}$ & $94.67 \pm 15.62$ & $79.67 \pm 28.13$ & $89.47 \pm 25.69$ & 0.052 \\
\hline Complications & & & & \\
\hline $\begin{array}{l}\text { Richmond's Agitation Score } \\
\text { a)agitated/calm/sedated }\end{array}$ & $0 / 28 / 2$ & $3 / 24 / 3$ & $3 / 27 / 0$ & 0.19 \\
\hline $\begin{array}{l}\text { b)Cough mild/moderate/severe } \\
\text { Nausea/vomiting }\end{array}$ & $3 / 25 / 2$ & $1 / 23 / 6$ & $3 / 24 / 3$ & 0.46 \\
\hline d)Brady/tachyarrythmia & $1(3.33 \%)$ & & $4(13.33 \%)$ & 0.064 \\
\hline e)Respiratory depression & None & None & None & - \\
\hline f) Convulsions & None & None & None & - \\
\hline
\end{tabular}

$\mathrm{n}=$ number of patients 

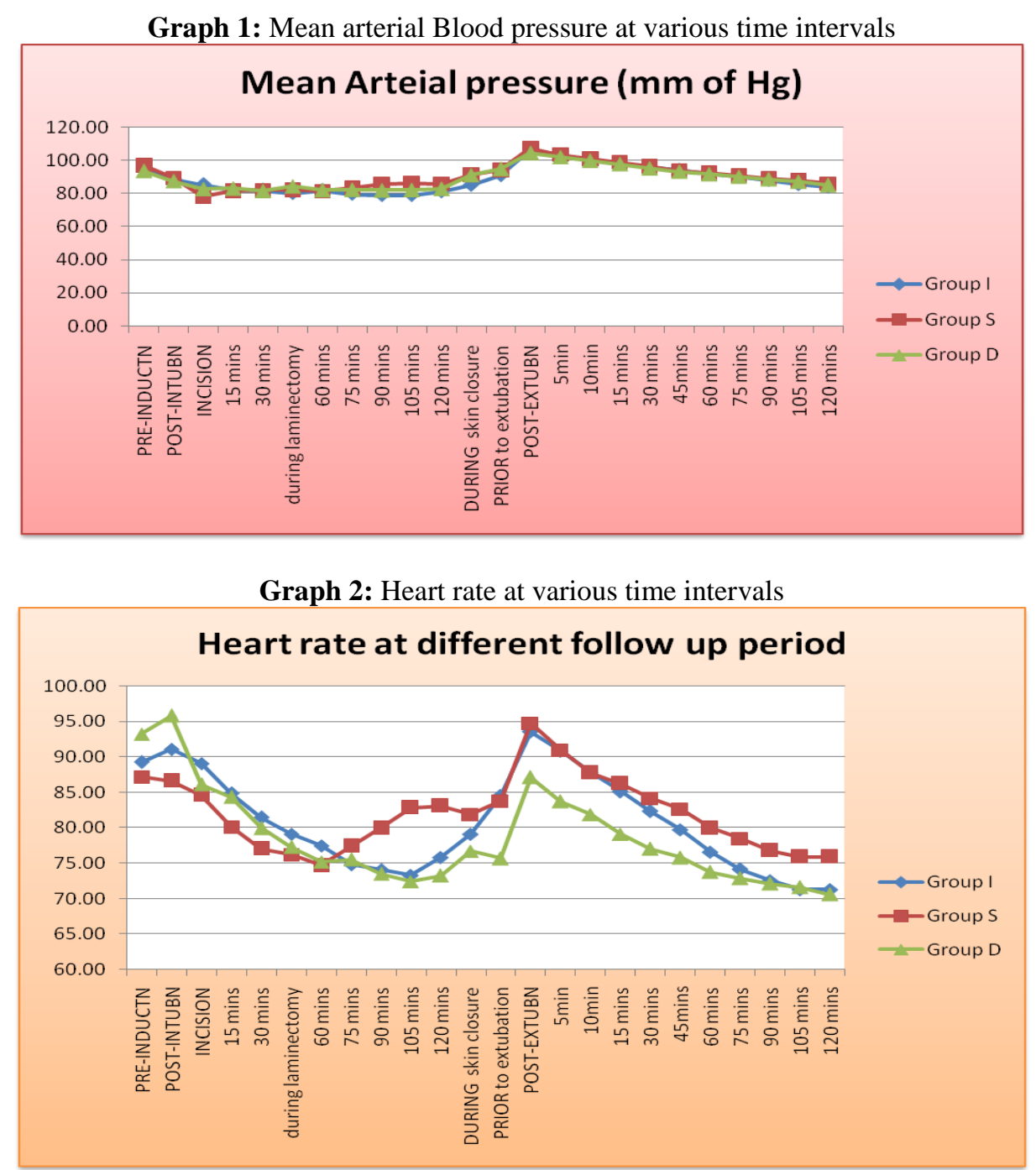

IV. Conclusion

Desflurane has low blood-gas and tissue-blood partition coefficients leading to a more rapid wash in and wash-out as compared to other halogenated hydrocarbons [9]. According to these pharmacokinetic properties of desflurane we assumed faster recovery and our results approved this hypothesis. Our studies demonstrated shorter times to emergence, extubation and recovery with desflurane than with sevoflurane and isoflurane. Another study compared these two drugs in children posted for spinal dysraphism and they too found significant reduction in emergence time and extubation time with desflurane than with sevoflurane[10].This is advantageous in spine surgeries where early awakening helps in early neurological evaluation and hence hasten the emergent action if required in case patient underwent any neurologic deficit .

We observed shorter emergence time as well as time to extubation and recovery with the use of desflurane. There are multiple studies comparing desflurane with either isoflurane or sevoflurane in neurosurgical patients. They have observed similar results. Some workers used desflurane and sevoflurane in outpatient anaesthesia and found significant reduction in time to eye opening, time to follow commands and orientation time in desflurane as compared to sevoflurane[11]. In yet another study shorter extubation and recovery times were observed with desflurane than with sevoflurane but similar mean emergence time and intra operative as well as postoperative rate of complications[6].

On the contrary one study reflected comparable emergence, extubation and recovery times between sevoflurane and desflurane[12]. Other workers found that although time to respond to verbal commands was shorter with desflurane than sevoflurane but time to emergence was similar[13].Although they considered time to emergence as time period from discontinuation of nitrous oxide to tracheal extubation. It was observed that the emergence time and extubation times reduced significantly in outpatient surgeries but recovery of cognitive function was similar between sevoflurane and desflurane[14]. In studies comparing desflurane with isoflurane it was reported that the time to eye opening and obeying verbal commands reduced to half with use of desflurane 
compared to isoflurane in adults[15]. This rapid emergence may provide an additional benefit in reducing the incidence of post operative complications associated with somnolence like hypoxemia and intermittent airway obstruction[16]. In our study the incidence of cough and post operative nausea, vomiting was comparable in all three groups. Most of the patients were calm. None had respiratory depression or cardiac arrhythmias. Similar observations were done in another study[12]. Some workers comparing propofol, desflurane and isoflurane in supratentorial tumors have observed nausea vomiting in two patients each in propofol and desflurane groups; and convulsions in two patients each in sevoflurane and desflurane groups[13]. Although we did not observe convulsions in any group.

Intra operative as well as post operative haemodyanamic stability is crucial in any neurosurgery. In our study we observed that all the three agents had comparable mean arterial pressures at most of the times during observation period. Similar observations were made in a recent study where desflurane was associated with comparable mean arterial blood pressures except during laminectomy and dural incision where there was a rise[13]. This increase could be the consequence of increased sympathetic stimulation due to high inspired concentrations of desflurane at more painful surgical stages[17,18]. We observed heart rate in a higher range with sevoflurane. Other workers also observed similar effect on heart rate with sevoflurane in their study comparing propofol, sevoflurane and desflurane[13]. However such increase was within acceptable limits and no treatment was required. From the present study we draw the conclusion that emergence characteristics with the use of desflurane are more favourable as compared to sevoflurane and isoflurane in adult patients undergoing spine surgeries under general anaesthesia .This may remarkably improve the neurological outcome in these patients. It is safe agent. Hence use of desflurane should be encouraged in spine surgeries.

\section{References}

[1]. Cheriyan T, Maier SP 2nd, Bianco K, Slobodyanyuk K, Rattenni RN, Lafage V et al. Efficacy of tranexamic acid on surgical bleeding in spine surgery: a meta-analysis. Spine J. 2015 ;15: 752-61.

[2]. Jindal R, Kumra VP, Narani KK, Sood J. Comparison of maintenance and emergence characteristics after desflurane or sevoflurane in outpatient anaesthesia. Indian J Anaesth 2011; 55: 36-42

[3]. Yildiz K, Bicer C, Aksu R, Dogru K, Madenoglu H,Boyaci A. A comparision of 1 minimum alveolar concentration desflurane and 1 minimum alveolar concentration isoflurane anesthesia in patients undergoing craniotomy for supratentorial lesions. Curr Ther Res Clin Exp. 2011;72:49-59.

[4]. Singh D, Rath GP, Dash HH, Bithal PK. Sevoflurane provides better recovery as compared with isoflurane in children undergoing spinal surgery. J Neurosurg Anesthesiol .2009; 21:202-6.

[5]. Khan BA, Guzman O, Campbell NL, Walroth T, Tricker JL, Hui SL et al. Comparison and agreement between the Richmond Agitation-Sedation Scale and the Riker Sedation-Agitation Scale in evaluating patients' eligibility for delirium assessment in the ICU. Chest. 2012; 142: 48-54.

[6]. Magni G, Rosa IL, Melillo G, Savio A, Rosa G. A comparison between sevoflurane and desflurane anesthesia in patients undergoing craniotomy for supratentorial intracranial surgery. Anesth Analg 2009; 109: 567-71.

[7]. Aldrete JA. The post-anaesthesia recovery score revisited. J Clin Anesth.1995; 7: 89-91.

[8]. Wewers ME, Lowe N K. A critical review of visual analogue scales in the measurement of clinical phenomena. Res Nurs Health 1990; 13:227-36.

[9]. Loscar M, Allhofft T, Otte E, Conzen P,Peter K .Awakening from anesthesia and recovery of cognitive functions after desflurane or isoflurane. Anaesthesist.1996; 45: 140-5.

[10]. Gupta P, Rath GP, Prabhakar H, Bithal PK. Comparison between sevoflurane and desflurane on emergence and recovery characteristics of children undergoing surgery for spinal dysraphism. Indian J Anaesth 2015; 59: 482-7.

[11]. White PF, Tang J, Wender RH, Yumul R, Stokes OJ, Sloninsky A et al. Desflurane versus sevoflurane for maintenance of outpatient anesthesia: the effect on early versus late recovery and peri operative coughing. Anesth Analg.2009; 109: 387-93.

[12]. Dube SK, Pandia MP, Chaturvedi A, Bithal P, Dash HH. Comparison of intraoperative brain condition, hemodynamics and postoperative recovery between desflurane and sevoflurane in patients undergoing supratentorial craniotomy. Saudi $\mathrm{J}$ Anaesth .2015; 167-73

[13]. Bastola P, Bhagat H, Wig J. Comparative evaluation of propofol, sevoflurane and desflurane for neuroanaesthesia: A prospective randomised study in patients undergoing elective supratentorial craniotomy. Indian J Anaesth 2015; 59:287-94

[14]. Nathanson MH, Fredman B, Smith I, White PF. Sevoflurane versus desflurane for outpatient anesthesia: A comparison of maintenance and recovery profiles. Anesth Analg.

[15]. $\quad$ 1995; 81: 1186-90.

[16]. Beaussier M, Deriaz H, Abdelahim Z, Aissa F, Lienhart A. Comparative effects of desflurane and isoflurane on recovery after long lasting anaesthesia. Can J Anaesth.1998; 45: 429-34.

[17]. Moller JT, Wittrup M, Johansen SH. Hypoxemia in the postanesthesia care unit: an observer study.Anesthesiology.1990; $73:$ 890-5.

[18]. Ebert TJ, Muzi M. Sympathetic hyperactivity during desflurane anesthesia in healthy volunteers.A comparison with isoflurane. Anesthesiology .1993; 79:444-53.

[19]. Weiskopf RB, Moore MA, Eger EI 2nd, Noorani M, McKay L,Chortkoff et al. Rapid increase in desflurane concentration is associated with greater transient cardiovascular stimulation than with rapid increase in isoflurane concentration in humans. Anesthesiology. 1994; 80: 1035-45. 